\title{
Optimizing the Water-Oil Emulsification Process for Developing CPC Microspheres
}

\author{
Caroline de Oliveira Renó ${ }^{a *}$, Mariana Motisuke ${ }^{a}$ \\ ${ }^{a}$ Bioceramics Laboratory, Science and Technology Institute - UNIFESP, São José dos Campos, SP, Brazil
}

Received: March 2, 2016; Revised: August 16, 2016; Accepted: September 18, 2016

\begin{abstract}
Spherical calcium phosphate cement carriers were synthesized by water/oil emulsion. A $2^{3}$ factorial design was employed in order to optimize the size and form of the microspheres. Stirring speed, liquid-to-powder ratio and cement paste-to-oil ratio were varied in two different levels and the response variable was the microsphere's sphericity. The results showed that cement's setting reaction was responsible for stabilizing the microspheres within the oil phase resulting in a low crystalline hydroxyapatite. The sizes varied from 6.29 to $64.23 \mu \mathrm{m}$. From the factors studied, the stirring velocity and the interaction between the $\mathrm{L} / \mathrm{P}$ ratio with the $\mathrm{P} / \mathrm{O}$ ratio are the ones that are more effective in controlling microspheres' sphericity. The results suggest that the methodology studied may provide microspheres with appropriate properties to deliver cells and/or drugs without inducing inflammatory reactions.
\end{abstract}

Keywords: calcium phosphate cement, microspheres, water/oil emulsion, alpha- tricalcium phosphate, factorial design.

\section{Introduction}

Materials based on calcium phosphates $(\mathrm{CaP})$ have been used in the repair of bone tissue as dense blocks, scaffolds and granules ${ }^{1}$. In the last few years, $\mathrm{CaP}$ granules and particulates had an increase in their applicability due to their higher specific surface area allowing greater contact area with body fluids and, consequently, a higher rate of in vivo resorption and cell adhesion ${ }^{1-4}$.

$\mathrm{CaP}$ granules may be applied for filling bone defects in regions that do not require high mechanical strength ${ }^{2}$ and for carrying drugs and biomolecules ${ }^{5-7}$ that would assist and/ or accelerate the treatment of diseases, induce the growth of new bone tissues which may lead to a delay in the need for bone replacement surgeries ${ }^{8}$. In these cases, controlling the size and the shape of the granules is crucial since irregular shapes may cause inflammatory reactions, and would make bone formation slower when compared to uniform and more spherical particles ${ }^{1,9,5,10}$.

Commonly, the production of ceramic microspheres requires two steps: (i) microspheres consolidation and; (ii) microspheres stabilization which can be achieved by sintering or processes that involves gellification or crosslinking of organic phases ${ }^{1}$. Nevertheless, these processes are low yield, difficult in controlling the granules shape and, in addition, some processes use toxic substances such as, paraffin ${ }^{9,6,11}$.

One way of produce ceramic microspheres without the need of a subsequent sinterization step would be by the formation of water/oil emulsions ( $\mathrm{W} / \mathrm{O})$ in which calcium phosphate cements are the hydrophilic phase and a vegetable

\footnotetext{
*e-mail: c.reno@unifesp.br
}

oil the lipophilic phase. Hence, the stabilization of these microspheres would occur after a cementation reaction ${ }^{12}$.

Calcium phosphate cements (CPCs) are considered advanced bioceramics due to its ability to form a moldable paste that hardens spontaneously and may be applied in vivo for replacing and/or treating damaged or injured bone tissues ${ }^{10,12-14}$ They are bioactive, biocompatible, osteoconductive, and resorbable $\mathrm{e}^{4,5}$ key properties that enhance the biological behavior of any biomedical implant. The intrinsic porosity of CPCs is also crucial as it enhances the resorption rate of the material in addition to promoting increased surface area available for interaction with biological media and incorporation of drugs ${ }^{10,14}$.

Some researchers employed emulsions of calcium phosphate pastes to fabricate microspheres and scaffolds ${ }^{1,15}$. Bohner studied the influence of emulsifiers in CPC emulsions to obtain scaffolds and microspheres ${ }^{15}$. From this work, it can be mentioned that: (i) inversion from $\mathrm{O} / \mathrm{W}$ phase to $\mathrm{W} / \mathrm{O}$ phase occurs naturally when the oil fraction exceeds 60 vol. \%; (ii) the addition of emulsifiers change the volume which the phase inversion occurs; (iii) increasing the oil fraction leads to an increase on stirring time and granules could be obtained

In another study, Perez et al. used water-oil emulsion (W/O) for the formation of calcium deficient hydroxyapatite (CDHA) microspheres, starting from the paste of calcium phosphate cement as the hydrophilic phase ${ }^{1}$. They investigated some factors that can influence on the formation of the microspheres, without changing the amount of oil. As a result, they obtained uniform and small microspheres with sizes between 100 and $900 \mu \mathrm{m}$ depending on the condition used. 
According to what has been presented, the development of spherical granules is consistent. Therefore, the main objective of this study is to optimize the synthesis of calcium phosphate microspheres, which may be used as an improved drug delivery system. For this purpose, CPC microspheres were prepared by W/O emulsion.

\section{Material and Methods}

\subsection{Calcium Phosphate Cement Microspheres}

CPC microspheres were obtained by water-oil emulsion where apatite cement was the hydrophilic phase and sunflower oil (Liza, Brazil) was the lipophilic phase. CPC's solid phase was [alpha]-tricalcium phosphate $(\alpha$-TCP) which was obtained by solid state reaction at $1300^{\circ} \mathrm{C}$ of " $\mathrm{Mg}$-free" $\mathrm{CaCO}_{3}$ and $\mathrm{CaHPO}_{4}$, as published elsewhere ${ }^{16}$. The powder was milled in a horizontal ball mill for 96 hours and its mean particle size was $2.82 \mu \mathrm{m}$ with a granulometric distribution between $1.03 \mu \mathrm{m}$ and $7.28 \mu \mathrm{m}$, and specific surface area was $1.63 \mathrm{~m}^{2} / \mathrm{g}$. CPC's liquid phase was a $2.5 \mathrm{wt} . \%$ of $\mathrm{Na}_{2} \mathrm{HPO}_{4}$ (Synth, Brazil) aqueous solution. Cement setting time was determined by Gilmore needle ${ }^{17}$.

The W/O emulsion process was made as follow: the cement paste was vigorously stirred (Ultra-Turrax T18 IKA $^{\circledR}$-WERKE, Germany) into the oil phase until CPC setting time was achieved resulting in a water-oil emulsification ${ }^{1,12,15}$. After phase segregation, the oil was removed by filtration and the CPC microspheres were extracted with 0.1 vol. $\%$ of surfactant (Tween 80; Synth, Brazil) dissolved in Ringer ${ }^{\circledR}$ solution. Afterwards, the remaining oil phase was removed with acetone (Synth, Brazil). The microspheres were immersed in Ringer ${ }^{\mathbb{B}}$ solution for 7 days to guarantee that setting reaction was complete.

The influence of liquid-to-powder ratio (L/P ratio), cement paste-to-oil ratio ( $\mathrm{P} / \mathrm{O}$ ratio) and stirring velocity on microspheres formation was analyzed by a $2^{3}$ factorial design with triplicate in the central point. Experiments were carried out in random order. The experiments developed in this work are summarized in Table 1.

Microspheres sphericity and mean size were determined by scanning electron microscopy (SEM) using the software ImageJ (version 1.49) for size measurements. Sphericity was determined using Equation 1, which allows obtaining values higher than one, since the microsphere can be larger both vertically and horizontally.

Sphericity $=[$ Mean diameter in horizontal/Mean diameter in vertical] (1)

A factorial design analysis, with a confidence level of 95 $\%$, has been performed on Minitab ${ }^{\circledR}$ release 16.1 to verify the influence of the factors and the interaction between them on the sphericity of the microspheres.
Table 1: Factorial design experiments.

\begin{tabular}{lccc}
\hline Nomenclature & $\begin{array}{c}\text { Liquid to } \\
\text { powder ratio } \\
(\mathrm{mL} / \mathrm{g})\end{array}$ & $\begin{array}{c}\text { Cement paste } \\
\text { to oil ratio } \\
(\mathrm{v} / \mathrm{v})\end{array}$ & $\begin{array}{c}\text { Stirring } \\
\text { velocity } \\
(\mathrm{rpm})\end{array}$ \\
\hline MS1 & 0.5 & 0.020 & 11000 \\
MS2 & 0.7 & 0.020 & 3500 \\
MS3 & 0.6 & 0.015 & 7250 \\
MS4 & 0.5 & 0.010 & 11000 \\
MS5 & 0.6 & 0.015 & 7250 \\
MS6 & 0.7 & 0.010 & 11000 \\
MS7 & 0.5 & 0.010 & 3500 \\
MS8 & 0.7 & 0.020 & 11000 \\
MS8 & 0.6 & 0.015 & 7250 \\
MS10 & 0.5 & 0.020 & 3500 \\
MS11 & 0.7 & 0.010 & 3500 \\
\hline
\end{tabular}

\subsection{Microspheres characterization}

Crystalline phases formed during CPC setting reaction were analyzed by X-ray diffraction (X'Pert Pro - PANalytical$\mathrm{X}^{\prime}$ Celerator, $\mathrm{CuK} \alpha, \mathrm{Ni}$ filter, 10 a $50^{\circ}(2 \theta), 0.02 \% \mathrm{~s}, 45 \mathrm{kV}$ e $40 \mathrm{~mA}$ ). JCPDS files used for phase identification were 460905 for CDHA, 09-0348 for $\alpha$-TCP and 09-0169 for $\beta$-TCP.

The morphology of the microspheres was analyzed by scanning electron microscopy (FEI Quanta650 FEG) with the samples coated with gold (Bal-Tec SCD 050 Sputter Coater).

\section{Results}

Figure 1 shows the XRD patterns of the as synthesized $\alpha$-TCP and one microsphere condition obtained in the factorial design. For all formulations, all $\alpha$-TCP was transformed into calcium deficient hydroxyapatite (CDHA - JCPDS - 46-0905). No other crystalline phase was detected.

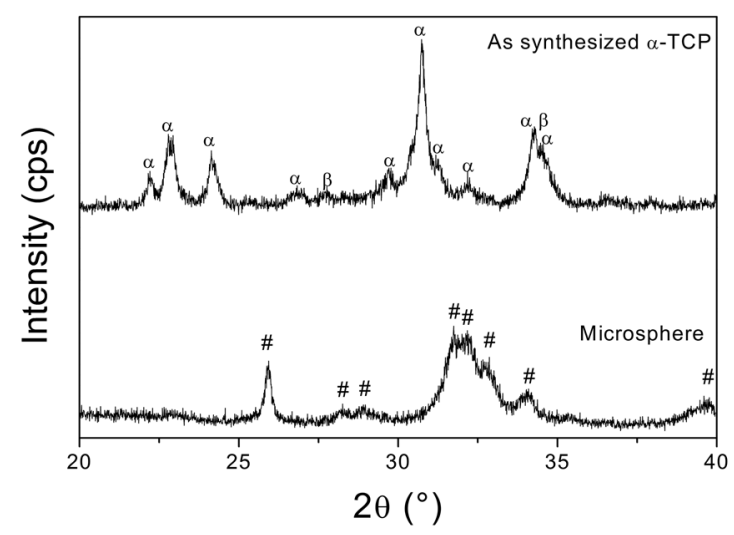

Figure 1: XRD patterns of the as synthesized $\alpha$-TCP and one microsphere condition obtained by W/O emulsion. ( $\alpha$ : $\alpha$-TCP, $\beta$ : $\beta$-TCP, \#- CDHA). 
The apatite phase formed during $\mathrm{CPC}$ setting reaction and $\mathrm{W} / \mathrm{O}$ oil emulsion has low crystallinity since the XRD lines present low intensity and are poorly defined; this fact may also be verified on the SEM micrographs of Figure 2, i.e. apatite crystals are needle like, and are extremely small.
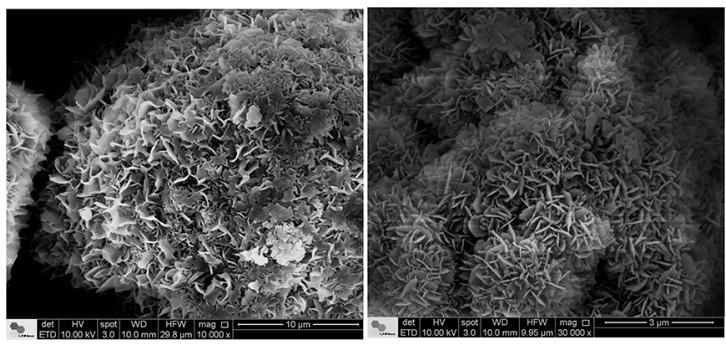

Figure 2: SEM micrograph showing the microstructure of the microspheres.

The influence of stirring speed, L/P ratio and cement paste-to-oil ratio on the sphericity and mean size are shown in Figure 3. Figure 4 displays the Pareto chart of the standardized factors and the interaction between them, by the vertical line, which represents the Length's Pseudo Error all terms that cross the line, are significant for the response, ie, for the spherical shape of the microspheres. From the analysis of variance, the stirring speed and the interaction between the liquid-to-powder ratio with the paste-to-oil ratio are significant factors in controlling the spherical shape of the microsphere, with p-value of 0.023 and 0.048 , respectively. The interaction between the factors can also be seen in Figure 5 , which shows the interaction plot. It can be verified that the only factors that present nonparallel lines is the $\mathrm{L} / \mathrm{P}$ ratio with the $\mathrm{P} / \mathrm{O}$ ratio, indicating the interaction between these factors, since when these lines do not intersect indicates that do not interact. It can also be noted that with a $\mathrm{P} / \mathrm{O}$ ratio of 0.01 , there is no influence on the sphericity, since the line present a small slope, but with a $\mathrm{P} / \mathrm{O}$ ratio of 0.02 , the sphericity is improved when was used an $\mathrm{L} / \mathrm{P}$ ratio of 0.5 .

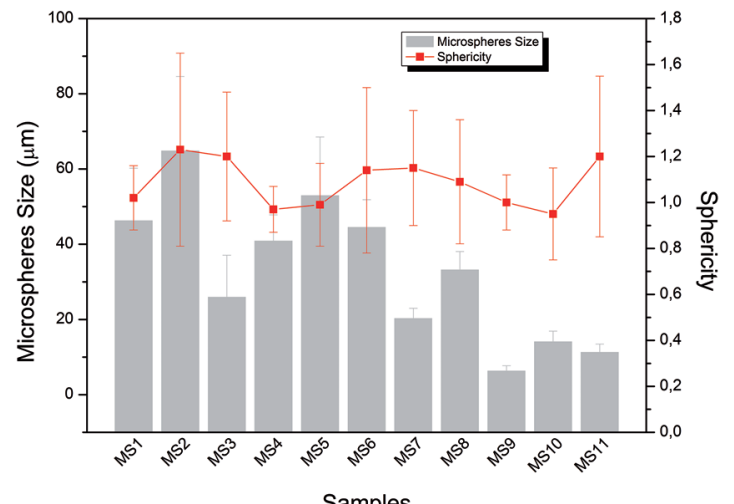

Figure 3: Mean Size and sphericity of the microspheres obtained by different processing conditions tested in the factorial design.

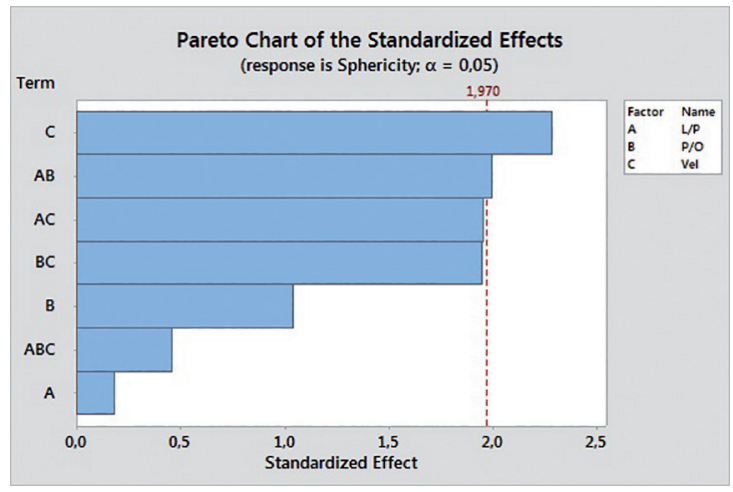

Figure 4: Pareto Chart of the standardized effects with a P-value $<0,05$.

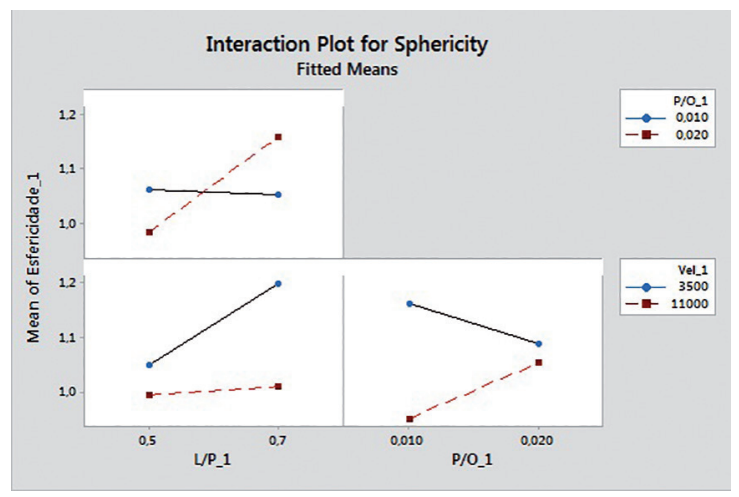

Figure 5: Interaction plot of the factors verified on the factorial design.

The ideal process condition would be when sphericity is the closest to the unity; therefore, from Figure 3 MS1 experiment $(\mathrm{L} / \mathrm{P}=0.5 \mathrm{~mL} / \mathrm{g}$; cement paste to oil ratio $=0.020$; stirring speed of $11000 \mathrm{rpm}$ and sphericity equal to 1.01 ) is this ideal point.

SEM images of the microspheres (Figure 6) show that all experiments led to the formation of granules. In addition, high stirring speeds and low $\mathrm{L} / \mathrm{P}$ ratio seems to be more effective for obtaining more homogeneous and more spherical microspheres. Indeed, sample MS1, ie the highest stirring speed and lowest $\mathrm{L} / \mathrm{P}$ ratio, resulted in very homogeneous microspheres with sphericities near to the unity. In fact, MS2 experiment (the highest $\mathrm{L} / \mathrm{P}$ ratio and the lowest stirring speed) formed irregular granules.

\section{Discussions}

As expected, CPC's setting reaction was not prevented by the emulsification process since all $\alpha$-TCP was transformed into calcium deficient hydroxyapatite (Figure 1$)^{10}$. The low crystallinity observed in the XRD pattern was also verified by Ginebra et al. ${ }^{18}$ when they used a fine powder of $\alpha$-TCP that has similar physical characteristics as the $\alpha$-TCP used in this work. Ginebra etal. has compared two powders, one coarse with $\mathrm{d}(50)$ of $10.88 \mu \mathrm{m}$ and one fine with $\mathrm{d}(50)$ of 2.22 


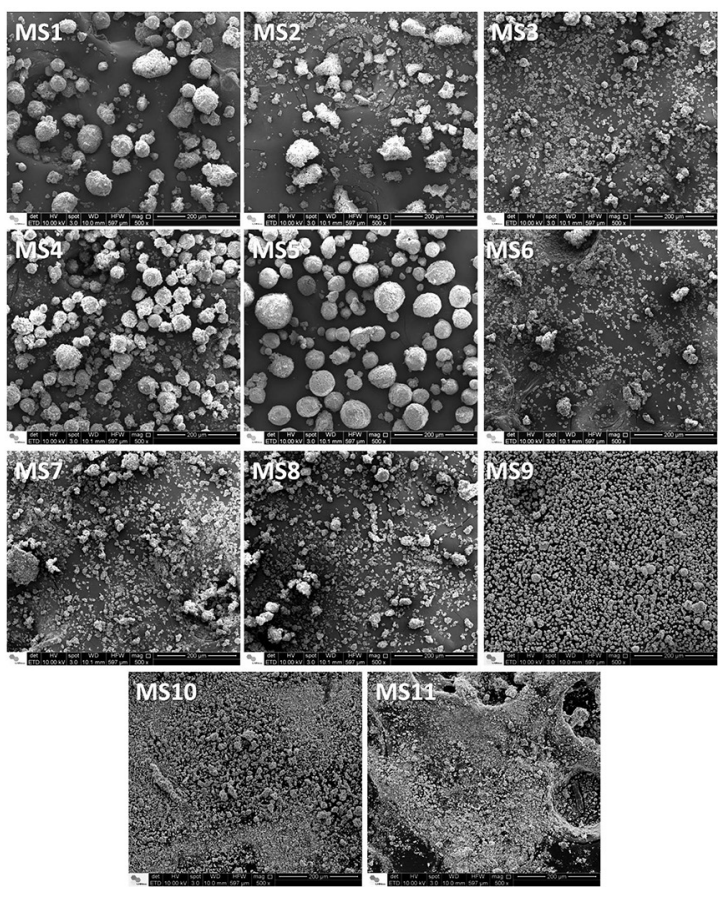

Figure 6: SEM micrographs presenting the microspheres obtained by the different processing conditions tested in the factorial design.

$\mu \mathrm{m}$. They observed that the fine one has formed CDHA with lower crystallinity, this was verified by the lower intensity and widening of the XRD peaks.

The W/O emulsion presented in this work was an efficient method for developing microspheres of calcium phosphate as no organic binders and no heat treatments were necessary to stabilize the microspheres. $\alpha$-TCP hydrolysis into CDHA which occurs by solubilization, crystallization and the entanglement of the crystals provide the mechanical resistance for the cement $^{10,13,19}$, leading to the stabilization of the microspheres ${ }^{1}$.

Analyzing the results of the factorial design, some conclusions could be taken into account, i.e. which factors has influence on the sphericity. First, the stirring velocity that has more influence on the sphericity of the microspheres; this factor has also influenced, mainly, on the size of the microspheres, as higher stirring velocity, smaller will be the microspheres with higher sphericity, which could be confirmed in Figures 3 and 6.

Second, the interaction between liquid-to-powder ratio and cement paste-to-oil ratio that has significant influence on the sphericity of the microspheres, with best results when the $\mathrm{L} / \mathrm{P}$ was 0.5 and the $\mathrm{P} / \mathrm{O}$ is 0.02 . The $\mathrm{L} / \mathrm{P}$ ratio it is related with the consolidation and the porosity of the microspheres. As lower this ratio, faster will be the consolidation of the microspheres, which avoids microspheres aggregation during agitation ${ }^{10}$. And the cement paste-to-oil ratio that had not been studied yet, but is a relevant factor that is related to the cost of the process and waste material. The statistical analysis demonstrate that when the $\mathrm{P} / \mathrm{O}$ ratio was 0.01 is not a significant variable to the sphericity of the microspheres (Figure 5), however when was $\mathrm{P} / \mathrm{O}$ ratio of 0.02 with a $\mathrm{L} / \mathrm{P}$ ratio of 0.5 , has improved the sphericity of the microspheres and the benefit that the amount of oil was reduced leading to a cost reduce of the process and it will produce less waste material, this is an advantage comparing with the emulsion made by Perez et al. ${ }^{1}$, that has fixed the cement paste-to-oil ratio in 0.01 . However, this amount of oil cannot be very small in order to avoid the inversion of phases $\mathrm{W} / \mathrm{O}$ to $\mathrm{O} / \mathrm{W}$, which would lead to formation of scaffolds instead of microspheres ${ }^{11,14}$.

The microspheres obtained have sizes between 6.29 and $64.23 \mu \mathrm{m}$ as shown in the graph of Figure 3 and in the micrographs (Figure 6). Some studies have evaluated the influence of the stirring speed in the water/oil emulsion to obtain microspheres. Perez et al. ${ }^{1}$ had used agitation speeds of 600 and $900 \mathrm{rpm}$ and obtained microspheres with sizes between 100 and $900 \mu \mathrm{m}$. In another study Komlev et al. ${ }^{6}$ had used stirring speed between 200 and $500 \mathrm{rpm}$, resulting microspheres with diameters between 50 and $2000 \mu \mathrm{m}$. Therefore, with an increase in the stirring speed, the size of the microspheres decreases. When a comparison is made, the microspheres obtained in this work has smaller sizes (around $45 \mu \mathrm{m}$ ) in the best conditions; since the speeds used are much higher when compared to those used in the literature studies.

The last conclusion of this factorial design is the ideal point, i.e. when the sphericity has the closest value to the unity, that is an important factor to evaluate, since sphericity close to one prevents possible inflammatory reactions ${ }^{5}$. That ideal point corresponds to the sample MS1, which presents 1.01 of sphericity; this was obtained when the L/P ratio was 0.5 , speed of $11000 \mathrm{rpm}$ and 0.02 of cement paste-to-oil. Other conditions that have sphericity closer to one were MS1, MS5 and MS9.

\section{Conclusion}

The water-oil emulsion is an effective method to produce microspheres of calcium phosphate cement. CPC setting reaction was responsible for stabilizing the microspheres within the oil phase; there is no need for further calcination. Among the factors studied in this work, it was observed that the stirring speed and the interaction between $\mathrm{L} / \mathrm{P}$ ratio and $\mathrm{P} / \mathrm{O}$ ratio have significant effects on the sphericity of the microspheres.

\section{Acknowledgements}

The authors would like to thank The São Paulo Research Foundation (FAPESP) for the financial support (Processes numbers 2012/21198-0, 2013/26248-9, 2011/09240-9, and 2013/19642-2) and João Paulo Barros Machado, PhD from the Laboratory of Sensors and Materials (LAS) of the National Institute of Space Research (INPE) for permitting XRD analysis and The Brazilian Synchrotron Light Source for permitting SEM analysis. 


\section{References}

1. Perez RA, Del Valle S, Altankov G, Ginebra MP. Porous hydroxyapatite and gelatin/hydroxyapatite microspheres obtained by calcium phosphate cement emulsion. Journal of Biomedical Materials Research Part B: Applied Biomaterials. 2011;97(1):156-166.

2. Gonda Y, Ioku K, Shibata Y, Okuda T, Kawachi G, Kamitakahara $\mathrm{M}$, et al. Stimulatory effect of hydrothermally synthesized biodegradable hydroxyapatite granules on osteogenesis and direct association with osteoclasts. Biomaterials. 2009;30(26):43904400 .

3. Sun R, Lu Y, Chen K. Preparation and characterization of hollow hydroxyapatite microspheres by spray drying method. Materials Science and Engineering: C. 2009;29(4):1088-1092.

4. Kim DH, Chun HH, Lee JD, Yoon SY. Evaluation of phase transformation behavior in biphasic calcium phosphate with controlled spherical micro-granule architecture. Ceramics International. 2014;40(4):5145-5155.

5. Santos C, Martins MA, Franke RP, Almeida MM, Costa MEV. Calcium phosphate granules for use as a 5-Fluorouracil delivery system. Ceramics International. 2009;35(4):1587-1594.

6. Komlev VS, Barinov SM, Koplik EV. A method to fabricate porous spherical hydroxyapatite granules intended for timecontrolled drug release. Biomaterials. 2002;23(16):34493454.

7. Malda J, Frondoza CG. Microcarriers in the engineering of cartilage and bone. Trends in Biotechnology. 2006;24(7):299304.

8. Holzapfel BM, Reichert JC, Schantz JT, Gbureck U, Rackwitz L, Nöth U, et al. How smart do biomaterials need to be? A translational science and clinical point of view. Advanced Drug Delivery Reviews. 2013;65(4):581-603.

9. Paul W, Sharma CP. Development of porous spherical hydroxyapatite granules: application towards protein delivery. Journal of Materials Science: Materials in Medicine. 1999;10(7):383-388.
10. Ginebra MP, Canal C, Espanol M, Pastorino D, Montufar EB. Calcium phosphate cements as drug delivery materials. Advanced Drug Delivery Reviews. 2012;64(12):1090-1110.

11. Komlev VS, Barinov SM, Girardin E, Oscarsson S, Rosengren $\AA$, Rustichelli F, et al. Porous spherical hydroxyapatite and fluorhydroxyapatite granules: processing and characterization. Science and Technology of Advanced Materials. 2003;4(6):503508.

12. Ginebra MP, Espanol M, Montufar EB, Perez RA, Mestres G. New processing approaches in calcium phosphate cements and their applications in regenerative medicine. Acta Biomaterialia. 2010;6(8):2863-2873

13. Dorozhkin SV. Calcium Orthophosphate Cements and Concretes. Materials. 2009;2(1):221-291.

14. Zhang J, Liu W, Schnitzler V, Tancret F, Bouler JM. Calcium phosphate cements for bone substitution: Chemistry, handling and mechanical properties. Acta Biomaterialia. 2014;10(3):10351049 .

15. Bohner M. Calcium Phosphate Emulsions: Possible Applications. Key Engineering Materials. 2001;192-195:765-768.

16. Motisuke M, Carrodeguas RG, Zavaglia CADC. Mg-Free Precursors for the Synthesis of Pure Si-doped $\alpha-\mathrm{Ca}_{3}(\mathrm{PO} 4)_{2}$. Key Engineering Materials. 2008;361-363:199-202.

17. ASTM International. ASTM C266-04: Standard Test Method for Time of Setting of Hydraulic-Cement Paste by Gillmore Needles. West Conshohocken: ASTM International; 2004.

18. Ginebra MP, Driessens FCM, Planell JA. Effect of the particle size on the micro and nanostructural features of a calcium phosphate cement: a kinetic analysis. Biomaterials. 2004;25(17):34533462 .

19. Espanol M, Perez RA, Montufar EB, Marichal C, Sacco A, Ginebra MP. Intrinsic porosity of calcium phosphate cements and its significance for drug delivery and tissue engineering applications. Acta Biomaterialia. 2009;5(7):2752-2762. 